\title{
Antigen processing for MHC presentation by autophagy
}

\section{Christian Münz}

\author{
Address: Viral Immunobiology, Institute of Experimental Immunology, University Hospital Zürich, Winterthurerstrasse 190, CH-8057 Zürich, \\ Switzerland \\ Email: christian.muenz@usz.ch
}

FI000 Biology Reports 2010, 2:6I (doi:I0.34I0/B2-6I)

The electronic version of this article is the complete one and can be found at: http://fl000.com/reports/biology/content/2/6I

\begin{abstract}
Autophagy delivers cytoplasmic constituents for lysosomal degradation. This catabolic pathway can be used to deliver intracellular antigens for major histocompatibility complex (MHC) class II presentation. In addition, recent evidence suggests that it also facilitates the processing of extracellular antigens for both MHC class I and II presentation.
\end{abstract}

\section{Introduction and context}

Classically, major histocompatibility complex (MHC) class I molecules present intracellular antigens to $\mathrm{CD}^{+}$ $\mathrm{T}$ cells and MHC class II molecules present extracellular antigens to $\mathrm{CD}^{+} \mathrm{T}$ cells during adaptive immune responses. However, professional antigen-presenting cells, such as dendritic cells (DCs), can process extracellular antigen for MHC class I presentation by a pathway called cross-presentation [1]. Vice versa, fragments of nuclear and cytosolic antigens have been found among natural MHC class II ligands [2,3], and it has been shown that some antigens can be presented by MHC class II after intracellular processing $[4,5]$. Some of these use autophagy to gain access to lysosomal degradation in MHC class II loading compartments [6-10].

Primarily, one particular autophagic pathway, called macroautophagy, has been implicated in intracellular antigen processing for $\mathrm{MHC}$ class II presentation to $\mathrm{CD} 4^{+}$ $\mathrm{T}$ cells. During macroautophagy an isolation membrane, which is thought to have originated from rough endoplasmic reticulum, the outer nuclear envelope membrane or the outer mitochondrial membrane [11-15], engulfs cytoplasmic constituents such as damaged organelles, protein aggregates and pathogens. Two ubiquitin-like systems with the Atg8 and Atg12 proteins at their heart are involved in extension of the autophagosomal membrane and substrate recruitment to its interior [16-18]. Upon completion of the resulting double membrane- surrounded autophagosome, these proteins are removed from the outer autophagosomal membrane, which then allows the fusion with lysosomes and late endosomes, such as multivesicular bodies (MVBs). The inner autophagosomal membrane and the autophagosome cargo are then broken down by lysosomal hydrolases. A subset of MVBs, known as MHC class II loading compartments, is used for antigen loading of MHC class II molecules. Autophagosomes fuse quite efficiently with these vesicles, resulting in MHC class II presentation of the autophagic cargo [19]. Thus, macroautophagy can deliver cytoplasmic antigens for MHC class II presentation to $\mathrm{CD} 4^{+} \mathrm{T}$ cells.

\section{Major recent advances}

In addition to the mechanistically fairly plausible intracellular antigen processing onto MHC class II molecules via macroautophagy, recent studies have also suggested that macroautophagy might assist with extracellular antigen processing for MHC class I and class II presentation. With respect to cross-presentation, two studies have demonstrated that viral and tumor antigens are more efficiently presented in trans to $\mathrm{CD} 8^{+} \mathrm{T}$ cells when the antigen donor cell can perform macroautophagy [20,21]. In the first of these studies, apoptosis-deficient mouse embryonic fibroblasts (Bax/Bak ${ }^{-1}$ MEFs) were more efficiently crosspresented after influenza A virus infection than wild-type MEFs. This cross-presentation was inhibited by small interfering RNA (siRNA)-mediated silencing of the essential macroautophagy gene product Atg5 [20]. In a second 
study, cross-presentation of the model antigen ovalbumin and the melanocyte differentiation antigen gp100 was diminished when macroautophagy was compromised in the antigen-donating epithelial and melanoma cell lines via siRNA knockdown of Atg6 and Atg12 [21]. These studies suggest that macroautophagy assists in the packaging of antigens for efficient cross-presentation.

In addition, macroautophagy seems to also facilitate the transport of endocytosed antigen to lysosomes for degradation as well as facilitating their loading onto MHC class II molecules. Enhanced delivery of phacocytosed material to lysosomes with the assistance of the molecular macroautophagy machinery was first described after Toll-like receptor 2 (TLR 2) stimulation of murine macrophages [22]. Furthermore, NOD2 stimulation enhanced macroautophagy, which enhanced lysosomal degradation of Salmonella [23]. This pathway also delivered
Salmonella-encoded antigens for MHC class II presentation and was sensitive to siRNA-mediated silencing of Atg5, Atg7 and Atg16L1. Interestingly, mutations in NOD2 and Atg16L1, which predispose for Crohn's disease, also compromise both bacterial clearance and MHC class II presentation of bacterial antigens to $\mathrm{CD}^{+} \mathrm{T}$ cells. Along the same lines, Atg5-deficient DCs are compromised in priming $\mathrm{CD}^{+} \mathrm{T}$ cell responses after herpes simplex virus infection and in efficiently processing extracellular ovalbumin for MHC class II presentation [24]. At the same time, priming of $\mathrm{CD}^{+} \mathrm{T}$ cell responses and cross-presentation on MHC class I are not affected. Finally, HIV infection of DCs seems to inhibit macroautophagy in order to increase virus production and to prevent viral antigen presentation to $\mathrm{CD}^{+} \mathrm{T}$ cells [25]. Macroautophagy stimulation enhances, whereas siRNA-mediated silencing of Atg 5 and Atg 8 decreases, HIV antigen presentation on MHC class II but not on MHC class I molecules. Altogether, these data

Figure I. Macroautophagy regulates cross-presentation and intracellular as well as extracellular antigen presentation on major histocompatibility complex (MHC) class II molecules

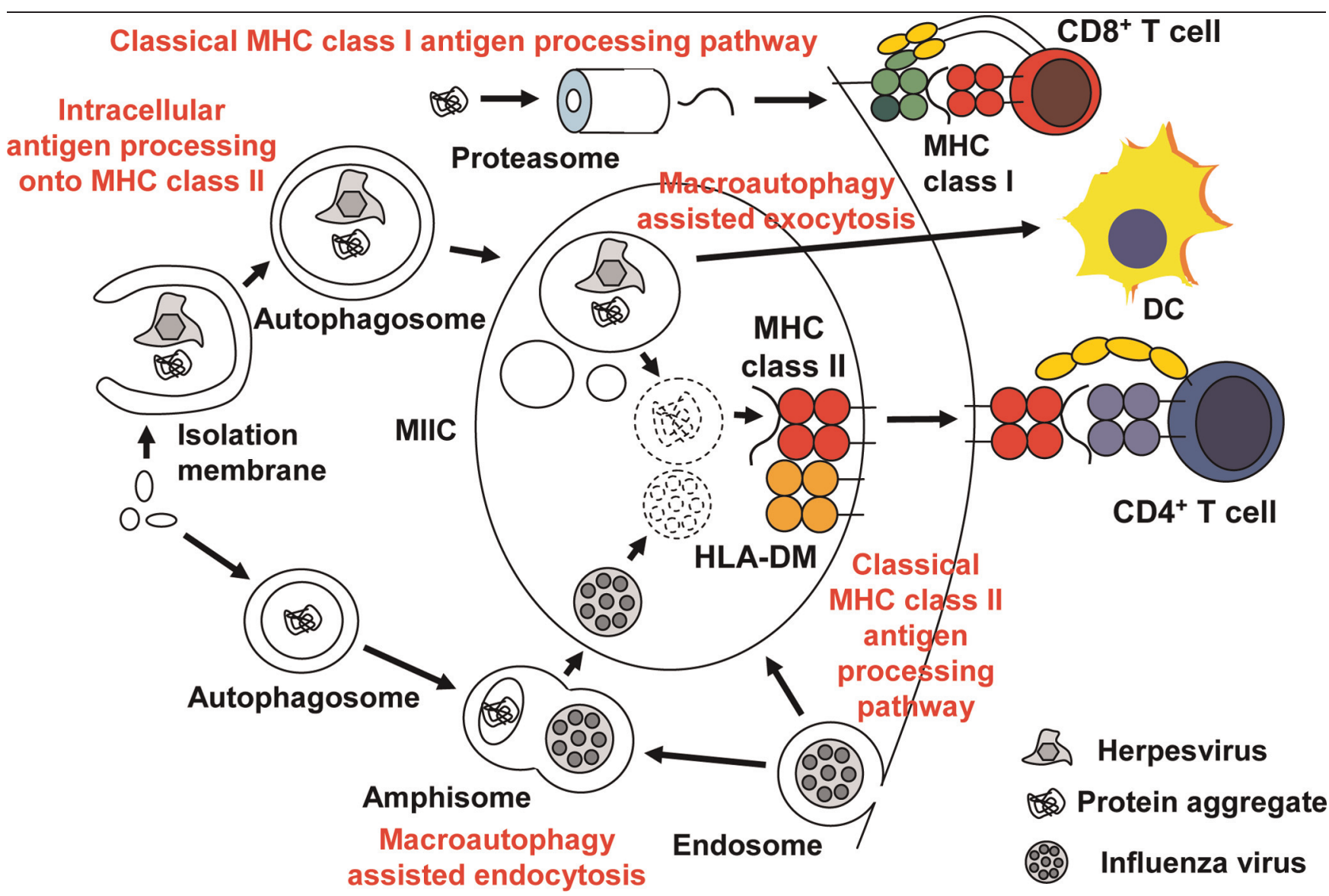

Autophagosomes, which form isolation membranes around cytoplasmic constituents, fuse with MHC class II loading compartments (MIICs), which are a subset of multivesicular bodies (MVBs). Autophagosomes fuse with MVBs either directly or after fusion with endosomes (forming amphisomes). Autophagic cargo can also escape from the MVBs via exocytosis and can then be efficiently cross-presented by dendritic cells (DCs). 
suggest that macroautophagy facilitates endosome cargo delivery for lysosomal degradation, which results in increased extracellular antigen processing for MHC class II presentation to $\mathrm{CD} 4^{+} \mathrm{T}$ cells.

\section{Future directions}

In light of these recent advances, it has become clear that macroautophagy regulates antigen presentation by MHC molecules beyond just intracellular antigen processing for $\mathrm{CD}^{+} \mathrm{T}$ cell stimulation. However, the mechanisms of antigen packaging by macroautophagy for crosspresentation and macroautophagy-mediated acceleration of endosome degradation by lysosomes remain elusive. In antigen donor cells, macroautophagy could provide the necessary energy to decorate dying cells with ligands for phagocytosis, such as, for example, phosphatidylserine, which needs to be flipped from the inner to the outer cell membrane leaflet in order to become an 'eat-me' signal [26,27]. Alternatively, autophagosome cargo could also be more efficiently released from MVBs via an alternative secretion pathway recently reported for the yeast Pichia pastoris and the slime mold Dictyostelium discoideum $[28,29]$. With respect to macroautophagic assistance for endosome fusion with lysosomes, it first needs to be clarified whether this represents an alternative use of Atgs, independent of macroautophagy, as was initially proposed [22], or whether amphisomes, the fusion vesicles between autophagosomes and endosomes, get targeted more rapidly to lysosomes. In a second step, the molecular basis for this enhanced targeting then needs to be elucidated. Irrespective of the mechanism, macroautophagic support for endosome fusion with lysosomes could explain why TLR coating increases antigen processing for MHC class II presentation [30]. Although much more needs to be done to characterize the underlying mechanisms, the recent studies discussed in this report suggest novel and exciting pathways in immunology, and cell biology in general, by which macroautophagy regulates endocytosis and exocytosis, in addition to its classical function in the degradation of cytoplasmic constituents by lysosomes.

\section{Abbreviations}

Atg, autophagy related gene; DC, dendritic cell; MEF, mouse embryonic fibroblast; $\mathrm{MHC}$, major histocompatibility complex; MVB, multivesicular body; siRNA, small interfering RNA; TLR, Toll-like receptor.

\section{Competing interests}

The author declares that he has no competing interests.

\section{Acknowledgments}

Research in the author's laboratory is supported by the National Cancer Institute of the National Institutes of
Health (R01CA108609 and R01CA101741), the Foundation for the National Institutes of Health (Grand Challenges in Global Health) and the Swiss National Science Foundation (310030_126995).

\section{References}

I. Amigorena S, Savina A: Intracellular mechanisms of antigen cross presentation in dendritic cells. Curr Opin Immunol 2010, 22:109-17.

2. Marrack P, Ignatowicz L, Kappler JW, Boymel J, Freed JH: Comparison of peptides bound to spleen and thymus class II. J Exp Med 1993, I 78:2173-83.

3. Dengjel J, Schoor $O$, Fischer $R$, Reich $M$, Kraus $M$, Müller $M$, Kreymborg K, Altenberend F, Brandenburg J, Kalbacher H, Brock R, Driessen C, Rammensee HG, Stevanovic S: Autophagy promotes MHC class II presentation of peptides from intracellular source proteins. Proc Natl Acad Sci U S A 2005, 102:7922-7.

FI000 Factor 3.0 Recommended

Evaluated by Peter Van Endert 23 Jun 2005

4. Jaraquemada $D$, Marti $M$, Long EO: An endogenous processing pathway in vaccinia virus-infected cells for presentation of cytoplasmic antigens to class II-restricted $\mathbf{T}$ cells. J Exp Med 1990, I 72:947-54.

5. Münz C, Bickham KL, Subklewe M, Tsang ML, Chahroudi A, Kurilla MG, Zhang D, O'Donnell M, Steinman RM: Human CD4 ${ }^{+} \mathbf{T}_{\text {Iympho- }}$ cytes consistently respond to the latent Epstein-Barr virus nuclear antigen EBNAI. J Exp Med 2000, 191:1649-60.

6. Brazil MI, Weiss S, Stockinger B: Excessive degradation of intracellular protein in macrophages prevents presentation in the context of major histocompatibility complex class II molecules. Eur J Immunol 1997, 27:1506-14.

7. Nimmerjahn F, Milosevic S, Behrends U, Jaffee EM, Pardoll DM, Bornkamm GW, Mautner J: Major histocompatibility complex class II-restricted presentation of a cytosolic antigen by autophagy. Eur J Immunol 2003, 33:I250-9.

8. Paludan C, Schmid D, Landthaler M, Vockerodt M, Kube D, Tuschl T, Münz C: Endogenous MHC class II processing of a viral nuclear antigen after autophagy. Science 2005, 307:593-6.

FI000 Factor 4.8 Must Read

Evaluated by Jonathan Howard 22 Feb 2005, Daniel Klionsky OI Mar 2005

9. Dorfel D, Appel S, Grunebach F, Weck MM, Muller MR, Heine A, Brossart P: Processing and presentation of HLA class I and II epitopes by dendritic cells after transfection with in vitro transcribed MUCI RNA. Blood 2005, I05:3199-205.

10. Jagannath C, Lindsey DR, Dhandayuthapani S, Xu Y, Hunter RL, Jr., Eissa NT: Autophagy enhances the efficacy of BCG vaccine by increasing peptide presentation in mouse dendritic cells. Nat Med 2009, I 5:267-76.

FI000 Factor 8.I Exceptional

Evaluated by Vojo Deretic 04 Mar 2009, Thomas W von Geldern 24 Mar 2009, George Yap 09 Apr 2009

II. Hayashi-Nishino M, Fujita N, Noda T, Yamaguchi A, Yoshimori T, Yamamoto A: A subdomain of the endoplasmic reticulum forms a cradle for autophagosome formation. Nat Cell Biol 2009, I I:|433-7.

FI000 Factor 6.0 Must Read

Evaluated by Michel Desjardins 23 Dec 2009

12. Yla-Anttila P, Vihinen H, Jokitalo E, Eskelinen EL: 3D tomography reveals connections between the phagophore and endoplasmic reticulum. Autophagy 2009, 5: 1 180-5.

FI000 Factor 6.0 Must Read

Evaluated by Daniel Klionsky OI Dec 2009 
13. English L, Chemali M, Duron J, Rondeau C, Laplante A, Gingras D, Alexander D, Leib D, Norbury C, Lippe R, Desjardins M: Autophagy enhances the presentation of endogenous viral antigens on MHC class I molecules during HSV-I infection. Nat Immunol 2009, 10:480-7.

FI000 Factor 6.0 Must Read

Evaluated by George Yap 09 Apr 2009

14. Hailey DW, Rambold AS, Satpute-Krishnan P, Mitra K, Sougrat R, Kim PK, Lippincott-Schwartz J: Mitochondria supply membranes for autophagosome biogenesis during starvation. Cell 2010, | 141:656-67.

FI000 Factor 4.8 Must Read

Evaluated by Ze'ev Ronai 01 Jun 2010, Yanzhuang Wang 01 Jul 2010

15. He C, Song H, Yorimitsu T, Monastyrska I, Yen WL, Legakis JE, Klionsky DJ: Recruitment of Atg9 to the preautophagosomal structure by AtgII is essential for selective autophagy in budding yeast. J Cell Biol 2006, I75:925-35.

16. He C, Klionsky DJ: Regulation mechanisms and signaling pathways of autophagy. Annu Rev Genet 2009, 43:67-93.

17. Ohsumi Y: Molecular dissection of autophagy: two ubiquitinlike systems. Nat Rev Mol Cell Biol 200I, 2:2I I-6.

18. Mizushima N, Levine B, Cuervo AM, Klionsky DJ: Autophagy fights disease through cellular self-digestion. Nature 2008, 45 I: 1069-75.

19. Schmid D, Pypaert M, Münz C: Antigen-loading compartments for major histocompatibility complex class II molecules continuously receive input from autophagosomes. Immunity 2007, 26:79-92.

FI000 Factor 6.0 Must Read

Evaluated by Vojo Deretic 09 Jan 2007

20. Uhl M, Kepp O, Jusforgues-Saklani H, Vicencio JM, Kroemer G, Albert ML: Autophagy within the antigen donor cell facilitates efficient antigen cross-priming of virus-specific CD8+ $T$ cells. Cell Death Differ 2009, 16:991-1005.

21. Li Y, Wang LX, Yang G, Hao F, Urba WJ, Hu HM: Efficient crosspresentation depends on autophagy in tumor cells. Cancer Res 2008, 68:6889-95.

22. Sanjuan MA, Dillon CP, Tait SW, Moshiach S, Dorsey F, Connell S, Komatsu M, Tanaka K, Cleveland JL, Withoff S, Green DR: Toll-like receptor signalling in macrophages links the autophagy pathway to phagocytosis. Nature 2007, 450:1253-7.

FI000 Factor 6.7 Must Read

Evaluated by Sergio Grinstein 07 Jan 2008, George Yap 08 Jan 2008

Daniel Klionsky 26 Feb 2008, Ulrich Schaible 17 Apr 2008
23. Cooney R, Baker J, Brain O, Danis B, Pichulik T, Allan P, Ferguson DJ, Campbell BJ, Jewell D, Simmons A: NOD2 stimulation induces autophagy in dendritic cells influencing bacterial handling and antigen presentation. Nat Med 2010, 16:90-7.

FI000 Factor 6.0 Must Read

Evaluated by Christian Müenz II Dec 2009

24. Lee HK, Mattei LM, Steinberg BE, Alberts P, Lee YH, Chervonsky A, Mizushima N, Grinstein S, Iwasaki A: In vivo requirement for Atg5 in antigen presentation by dendritic cells. Immunity 2010, 32:227-39.

25. Blanchet FP, Moris A, Nikolic DS, Lehmann M, Cardinaud S, Stalder R, Garcia E, Dinkins C, Leuba F, Wu L, Schwartz O, Deretic V, Piguet V: Human immunodeficiency virus-I inhibition of immunoamphisomes in dendritic cells impairs early innate and adaptive immune responses. Immunity 2010, 32:654-69.

26. Qu X, Zou Z, Sun Q, Luby-Phelps K, Cheng P, Hogan RN, Gilpin C, Levine B: Autophagy gene-dependent clearance of apoptotic cells during embryonic development. Cell 2007, 128:93।-46.

FI000 Factor 6.4 Must Read

Evaluated by Eric Baehrecke 2 I Mar 2007, Christoph Borner 26 Apr 2007

27. Mellen MA, de la Rosa EJ, Boya P: The autophagic machinery is necessary for removal of cell corpses from the developing retinal neuroepithelium. Cell Death Differ 2008, 15:1279-90.

28. Manjithaya R, Anjard C, Loomis WF, Subramani S: Unconventional secretion of Pichia pastoris AcbI is dependent on GRASP protein, peroxisomal functions, and autophagosome formation. J Cell Biol 2010, 188:537-46.

29. Duran JM, Anjard C, Stefan C, Loomis WF, Malhotra V: Unconventional secretion of Acbl is mediated by autophagosomes. J Cell Biol 2010, 188:527-36.

FI000 Factor 4.8 Must Read

Evaluated by Daniel Klionsky 02 Mar 2010, Kiyoshi Takeda $03 \mathrm{Mar}$ 2010, John Kyriakis 10 Mar 2010, Brad Marsh 14 Apr 2010

30. Blander JM, Medzhitov R: Toll-dependent selection of microbial antigens for presentation by dendritic cells. Nature 2006, 440:808-12.

FI000 Factor II.6 Exceptional

Evaluated by Christopher Karp 06 Mar 2006, Torben Lund 10 Mar 2006, Peter Van Endert 10 Mar 2006, Elizabeth Mellins 29 Mar 2006, David Branch Moody 29 Mar 2006, Dan Conrad I3 Apr 2006, Laurence Eisenlohr 24 Apr 2006, Etienne Joly 27 Apr 2006, Marcus Thelen 17 May 2006, Victor Nizet 13 Jun 2006 